\title{
Rotavirus vaccine and diarrhea mortality: quantifying regional variation in effect size
}

\author{
Christa L Fischer Walker ${ }^{*}$, Robert E Black
}

\begin{abstract}
Background: Diarrhea mortality remains a leading cause of child death and rotavirus vaccine an effective tool for preventing severe rotavirus diarrhea. New data suggest vaccine efficacy may vary by region.

Methods: We reviewed published vaccine efficacy trials to estimate a regional-specific effect of vaccine efficacy on severe rotavirus diarrhea and hospitalizations. We assessed the quality of evidence using a standard protocol and conducted meta-analyses where more than 1 data point was available.

Results: Rotavirus vaccine prevented severe rotavirus episodes in all regions; $81 \%$ of episodes in Latin America, 42.7\% of episodes in high-mortality Asia, 50\% of episodes in sub-Saharan Africa, $88 \%$ of episodes low-mortality Asia and North Africa, and $91 \%$ of episodes in developed countries. The effect sizes observed for preventing severe rotavirus diarrhea will be used in LiST as the effect size for rotavirus vaccine on rotavirus-specific diarrhea mortality.

Conclusions: Vaccine trials have not measured the effect of vaccine on diarrhea mortality. The overall quality of the evidence and consistency observed across studies suggests that estimating mortality based on a severe morbidity reduction is highly plausible.
\end{abstract}

\section{Background}

Diarrhea remains the second leading cause of death around the world for children under 5 years of age [1]. Because the majority of diarrhea deaths occur in the low and middle-income countries, the etiologic agents responsible for diarrhea deaths among young children are unknown. Using hospitalization data as a best estimate of severe diarrheal disease and a proxy for diarrhea mortality, it has been estimated that rotavirus may be responsible for up to $39 \%$ of child deaths, the majority of which occur in low and middle income countries [2].

Several rotavirus vaccines have been introduced in the US market since the late 1990s. The current vaccines include a monovalent attenuated human rotavirus vaccine and a pentavalent human-bovine reassortant vaccine. Previous reviews, including a Cochrane review and a systematic review recently published by our group have quantified the pooled efficacy of these vaccines on severe diarrheal disease as well as diarrhea mortality among children in developed countries and a selected group of Latin American middle-income countries [3,4].

\footnotetext{
*Correspondence: cfischer@jhsph.edu

Department of International Health, Johns Hopkins Bloomberg School of Public Health, Baltimore, MD, 21205, USA
}

Until recently, data from trials in sub-Saharan Africa and Asia had not been published and thus not yet included in meta-analyses of published effect sizes [5-8].

With the publication of the final results from trials in sub-Saharan Africa and Asia, it is critical to re-evaluate the evidence to date. The Lives Saved Tool (LiST) uses vaccine efficacy to model the total lives that could be saved with introduction and scale up of rotavirus vaccine in low- and middle-income countries. Because new data suggest substantial variation in vaccine efficacy by region, we estimate regional-specific vaccine efficacy on rotavirus mortality to be used in program planning by incorporation into LiST.

\section{Methods}

We previously conducted and published the results of a systematic review to identify studies assessing the effect of rotavirus vaccine on diarrhea incidence and mortality using the guidelines established by the Child Health Epidemiology Reference Group (CHERG) [3,9]. In brief, we conducted a literature search to indentify all Phase III rotavirus vaccine trials of marketed products as of January 2009. We reviewed more than 400 titles and abstracts, screened 17 full papers and included 5 papers

\section{Public Heath, Batimore, MD, 21205, USA \\ () Biomed Central}

(c) 2011 Fischer Walker and Black; licensee BioMed Central Ltd. This is an open access article distributed under the terms of the Creative Commons Attribution License (http://creativecommons.org/licenses/by/2.0), which permits unrestricted use, distribution, and reproduction in any medium, provided the original work is properly cited. 
in our final review. Since this review [5-8], 4 studies have been published providing additional data for Asia and sub-Saharan Africa, where previous data were not available.

We screened the newly published studies according to our original inclusion and exclusion criteria and abstracted key variables according to the CHERG adapted GRADE technique (Grading of Recommendations Assessment, Development and Adaptation) [10] for each of the following study outcomes: rotavirus hospitalizations, all diarrhea hospitalizations, incidence of rotavirus infections, and incidence of severe allcause diarrhea infections (Additional File 1) [9]. For this analysis we excluded studies that included children who received less than the recommended vaccine dose. Many of the pivotal studies led to multiple publications; we abstracted data from all publications (Additional File 1) but included only the data from the papers reporting the full 2 years of follow-up in our final meta-analysis. In some cases this was a smaller sub-group analysis, however these data were chosen because the final vaccine effect size will be applied to children beyond the first 12 mo of life. Likewise, in order to provide a better measure of the potential impact of the vaccine when implemented under routine conditions, we abstracted intent-to-treat data from case control studies. In a standardized summary table we described the overall quality of evidence and summarize the input data for rotavirus hospitalization and incidence of severe rotavirus infection as the best measures of serious rotavirus morbidity. For each outcome we grouped evidence into 5 distinct country groupings: developed, Latin America, low mortality Asia and North Africa, high mortality Asia, and sub-Saharan Africa (Table 1).

For outcomes and regions where more than one study had data available, we preformed both fixed and random effect meta-analyses using STATA statistical software. We reported the Mantel-Haenszel pooled relative risk and corresponding 95\% confidence interval (CI).

\section{Results}

We identified 2 studies in the Latin America region [11,12], 2 studies from sub-Saharan Africa [5,6], 1 study from the high mortality Asian countries [7], 2 studies with data from low mortality Asian and North African countries [7,8], and 2 studies from developed countries $[13,14]$ (Additional File 2). In Latin America, 1 study reported that rotavirus vaccine prevented $81 \%$ of cases of severe rotavirus and in high-mortality Asia, 1 study reported that rotavirus vaccine prevented $42.7 \%$ of severe rotavirus episodes. For the regions of sub-Saharan Africa, low-mortality Asia and North Africa, and developed countries we conducted meta-analyses for the
Table 1 Countdown to 2015 and GAVI eligible countries by under 5 mortality rate and region for use in applying rotavirus vaccine effect size

\begin{tabular}{|c|c|c|c|}
\hline Region/Country & $\begin{array}{c}<5 \\
\text { Mortality Rate }\end{array}$ & Region/Country & $\begin{array}{c}<5 \\
\text { Mortality Rate }\end{array}$ \\
\hline Developed & & Sub-Saharan Africa & \\
\hline Cuba & 6 & Eritrea & 55 \\
\hline Ukraine & 15 & Botswana & 57 \\
\hline Armenia & 22 & Madagascar & 57 \\
\hline Moldova & 17 & South Africa & 62 \\
\hline $\begin{array}{l}\text { Low mortality Asia } \\
\text { and North Africa }\end{array}$ & & Ghana & 68 \\
\hline China & 19 & Gabon & 69 \\
\hline Sri Lanka & 15 & Swaziland & 73 \\
\hline Egypt & 21 & $\begin{array}{l}\text { Sao Tome and } \\
\text { Principe }\end{array}$ & 78 \\
\hline Vietnam & 23 & Lesotho & 82 \\
\hline Latin America & & Kenya & 84 \\
\hline Mexico & 17 & Zimbabwe & 86 \\
\hline Brazil & 21 & Djibouti & 93 \\
\hline Peru & 21 & Senegal & 93 \\
\hline Nicaragua & 25 & Togo & 96 \\
\hline Honduras & 29 & Comoros & 102 \\
\hline Guyana & 35 & Gambia & 102 \\
\hline Guatemala & 40 & Ethiopia & 104 \\
\hline Bolivia & 50 & Tanzania & 105 \\
\hline Haiti & 86 & Sudan & 108 \\
\hline High mortality Asia & & Liberia & 110 \\
\hline Georgia & 29 & Malawi & 110 \\
\hline Mongolia & 29 & Rwanda & 111 \\
\hline DPR Korea & 33 & Cote d'Ivoire & 115 \\
\hline Philippines & 33 & Mauritania & 115 \\
\hline Azerbaijan & 34 & Benin & 117 \\
\hline Uzbekistan & 35 & Congo & 125 \\
\hline Solomon Islands & 36 & Uganda & 127 \\
\hline Kyrgyzstan & 37 & Nigeria & 138 \\
\hline Morocco & 37 & Mozambique & 139 \\
\hline Indonesia & 39 & Guinea & 140 \\
\hline Iraq & 44 & Zambia & 141 \\
\hline Turkmenistan & 45 & Equitorial Guinea & 147 \\
\hline Kiribati & 46 & Cameroon & 150 \\
\hline Nepal & 48 & Niger & 156 \\
\hline Bangladesh & 52 & Angola & 161 \\
\hline Timor Leste & 56 & Burundi & 165 \\
\hline Laos & 58 & Burkina Faso & 166 \\
\hline Tajikistan & 61 & CAR & 168 \\
\hline India & 66 & Somalia & 179 \\
\hline $\begin{array}{l}\text { Papua new } \\
\text { guinea }\end{array}$ & 66 & Mali & 191 \\
\hline Yemen & 66 & Sierra Leone & 191 \\
\hline Myanmar & 71 & Guinea-Bissau & 192 \\
\hline Bhutan & 79 & DR Congo & 193 \\
\hline Pakistan & 85 & Chad & 208 \\
\hline Cambodia & 87 & & \\
\hline Afghanistan & 192 & & \\
\hline
\end{tabular}


outcome of efficacy against severe rotavirus gastroenteritis and estimated that rotavirus vaccine prevented 50\% of severe rotavirus episodes in sub-Saharan Africa (Figure 1), 88\% of severe rotavirus episodes in low-mortality Asia and North Africa (Figure 2), and 91\% of severe rotavirus episodes in developed countries (Figure 3).

At the country level the effect of vaccine on severe rotavirus disease appears to be directly correlated with under 5 mortality in that countries with higher under 5 mortality rates have demonstrated lower vaccine efficacy (Figure 4). The only outcome with data from all regions was efficacy against severe rotavirus gastroenteritis; in addition, where hospitalization data were available the effect against severe rotavirus diarrhea was more conservative than the effect again rotavirus hospitalizations thus we chose to use the effect of the vaccine on incidence of severe rotavirus disease as the proxy for rotavirus mortality (Figure 5). Region specific estimates ranging from $42.7 \%$ for high-mortality Asian countries to $90.6 \%$ for developed countries will be incorporated into LiST for the effect of rotavirus vaccine on rotavirus specific mortality.

\section{Discussion}

In this review we present the first analysis of all rotavirus vaccine efficacy studies published for the currently recommended rotavirus vaccines with the intent of estimating region specific effect of the rotavirus vaccine on diarrhea mortality. We initially abstracted data on all diarrhea outcomes included in the publications. However, in this analysis we sought to estimate the effect of rotavirus vaccine on diarrhea mortality thus focused on the most severe study outcomes as the best proxy for an anticipated mortality reduction where mortality data are lacking. Studies measured reductions in severe rotavirus disease and rotavirus hospitalizations; we chose a final effect size based on reduction in severe rotavirus incidence as this outcome was measured in all geographic regions and was consistently the more conservative estimate as compared to reductions in rotavirus hospitalizations. Though vaccine trials have not directly measured the effect of vaccine on diarrhea mortality, two recent studies in Brazil and Mexico have shown marked reductions in diarrhea mortality in communities that achieved high rates of rotavirus vaccination $[15,16]$. For these reasons, we believe the overall quality of the evidence and consistency observed across studies suggests that estimating mortality based on a severe morbidity reduction is highly plausible.

Vaccine trials to date have been focused on severe diarrhea and thus have not included outcome measures to capture the effect of vaccine on diarrhea incidence of any severity. For this reason the LiST model does not include the effect of rotavirus vaccine on diarrhea incidence. Though it is expected that the rotavirus vaccine would have a small effect on all cause diarrhea incidence, there are no data to suggest the size of this effect [17]. Because the effect of vaccine on mortality is captured here, the small additional benefit via the diarrhea incidence pathway would be negligible in the model.

In this analysis we only included studies that assessed efficacy or effectiveness among fully vaccinated children. In our previous review we included two case control studies that categorized a child as vaccinated if he/she had received only 1 dose of vaccine [18,19]. The goal of LiST is to provide accurate estimates of an anticipated effect of an intervention on cause-specific mortality at a given coverage point. Because rotavirus vaccine coverage indicators are designed to measure the proportion of children who received the full vaccine dose, we estimated the effect size here including only fully vaccinated children to ensure consistency. We have not attempted

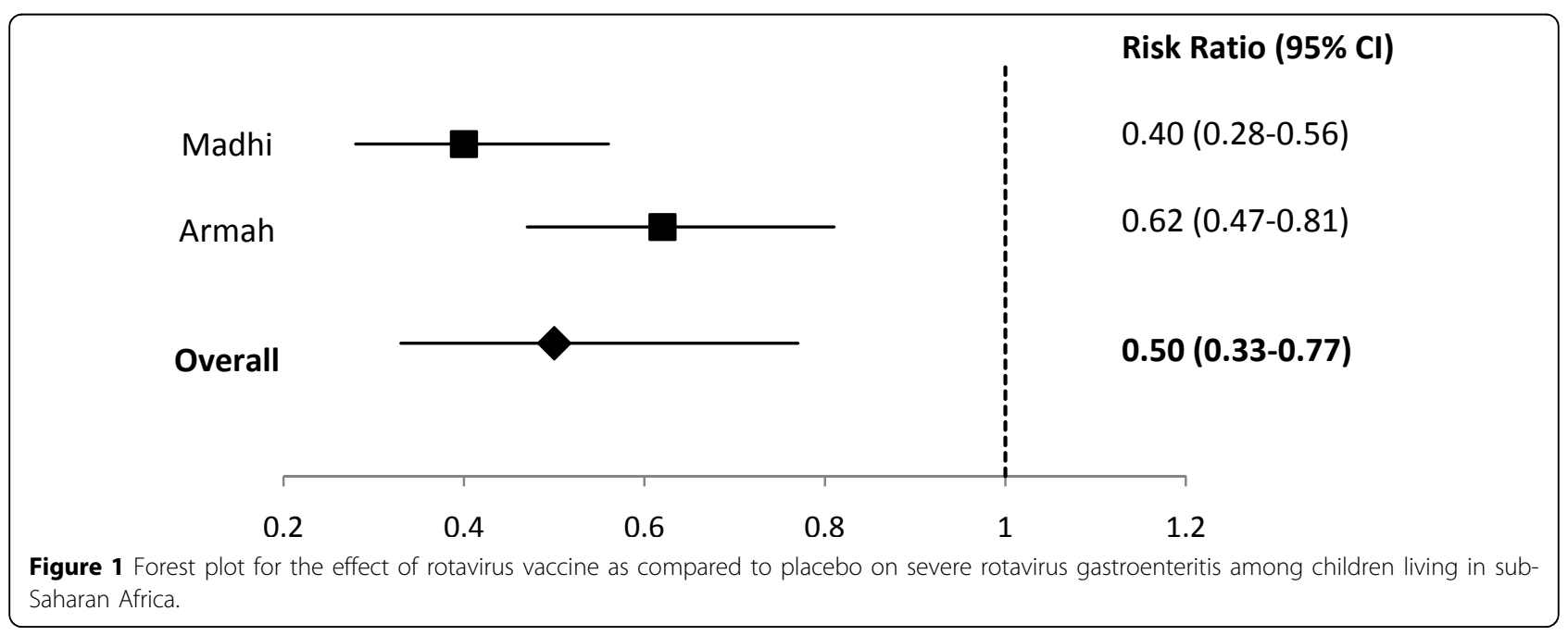




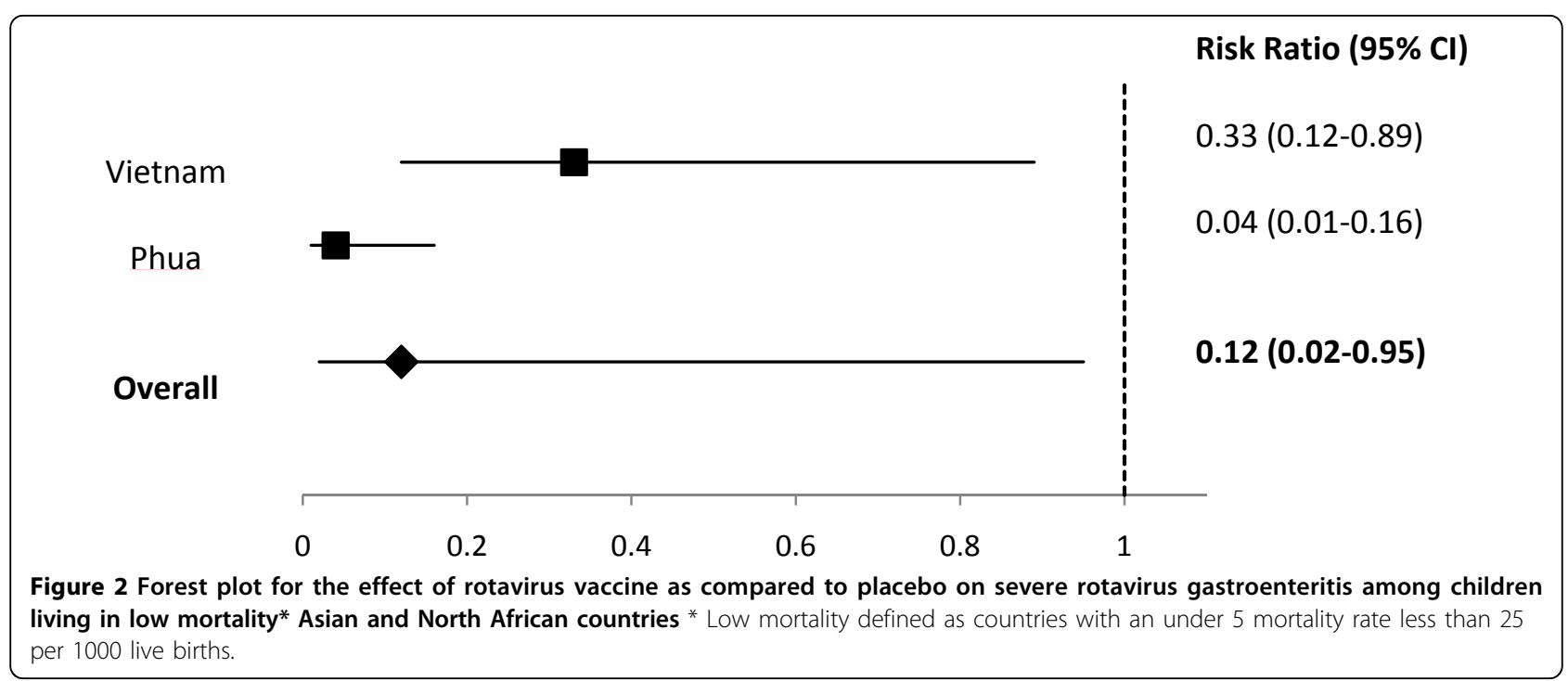

to capture any additional effect the vaccine may have with regard to population level herd immunity; studies to date have not been designed to capture this and thus a possible effect is impossible to quantify.

There are numerous hypotheses as to why the protective efficacy of the vaccine varies by region and study population with markedly lower protective efficacy rates in populations with high infant mortality. Some reasons may include variation in host response due to passive immunity via breastfeeding or underlying nutritional differences; differences in rates of severe disease; and variation in endemic disease versus seasonal peaks. It is also possible that bacteria and other viruses may remain important causes of severe morbidity in low-income settings as compared to children in high-income settings where improvements in water and sanitation have virtually eliminated these pathogens from the community setting. Co-infection with more than one potential pathogen in these settings is common and it is possible that the rotavirus found by sensitive assays in the stool is not always the organism causing the illness. The frequent encounter with fecal pathogens may also lead to "environmental enterpathy" which, while protecting the child to some degree from falling repeatedly ill due to routine pathogens, this may also create a hostile environment for eliciting a lower

\begin{tabular}{|l|l|l|}
\hline Vesikari & Risk Ratio (95\% Cl) \\
\hline
\end{tabular}




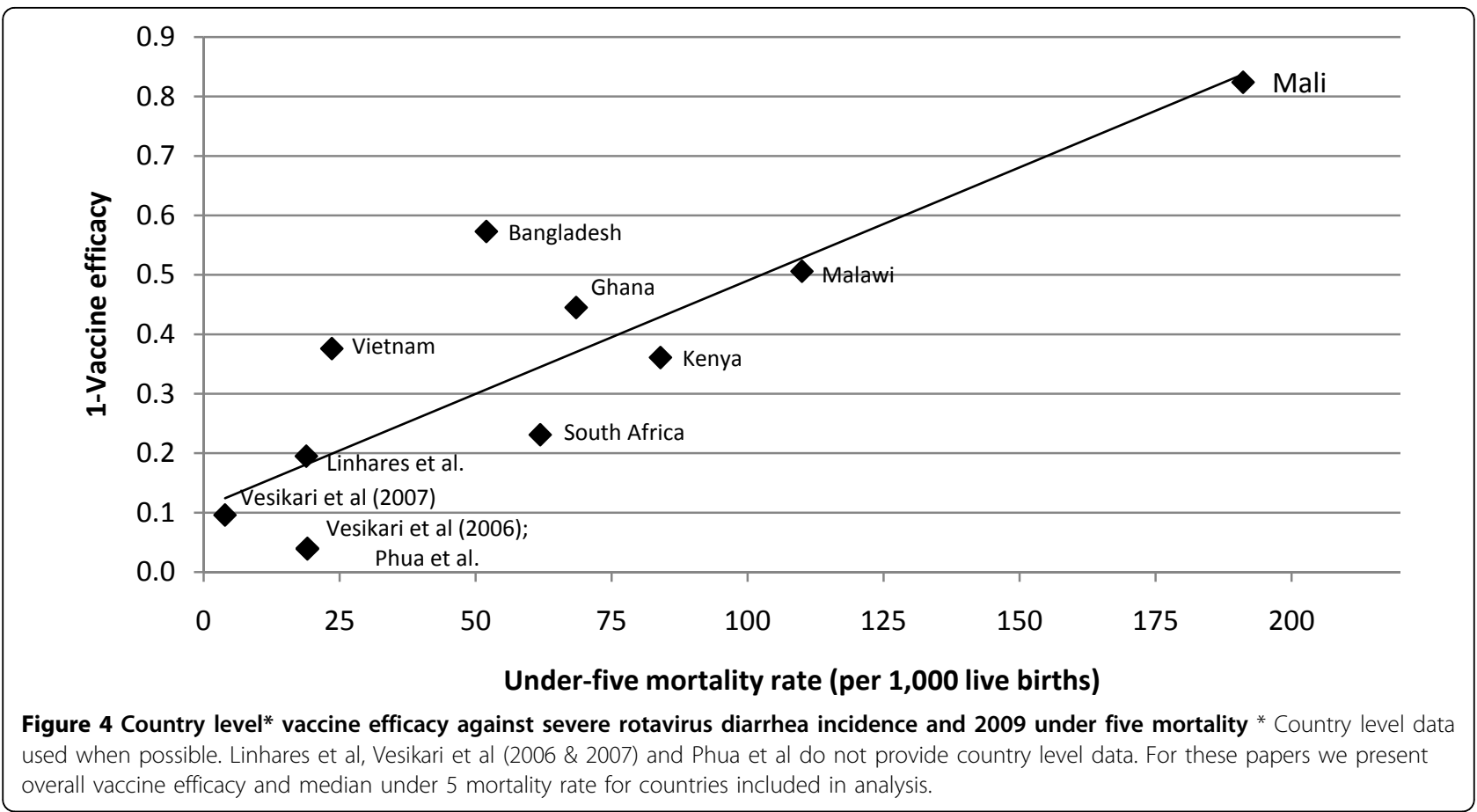

immune response to the vaccine [20]. There is also limited evidence to suggest that substantial variation in strains included in the vaccine and subsequent circulating stains in the community may cause lower effectiveness in the community, quantifying the effect of this variation across settings is difficult [21].
Unfortunately, the appropriate studies have not been done to determine which, if any, of these hypotheses explains the observed differences. Additional descriptive etiology studies are needed to more fully understand the role of various pathogens; including differences in rotavirus strains in causing severe

\begin{tabular}{|c|c|c|c|}
\hline \multicolumn{3}{|c|}{ Region } & $\begin{array}{l}\text { Final Effect Size } \\
\text { Relative Reduction }(95 \% \mathrm{Cl})\end{array}$ \\
\hline \multicolumn{3}{|c|}{$\begin{array}{l}\text { Latin America ( } n=1 ; 10 \text { Latin American } \\
\text { countries) 193events }\end{array}$} & $\longrightarrow \quad 81 \%(71.3-87.1 \%)$ \\
\hline \multicolumn{3}{|c|}{$\begin{array}{l}\text { Africa ( } n=2 ; 5 \text { African countries) } \\
304 \text { events }\end{array}$} & $49.7 \%(22.8-67.1 \%)$ \\
\hline \multicolumn{3}{|c|}{$\begin{array}{l}\text { High mortality Asia ( } n=1 ; 1 \text { country) } \\
89 \text { events }\end{array}$} & $42.7 \%(10.4-63.9 \%)$ \\
\hline \multicolumn{3}{|c|}{$\begin{array}{l}\text { Low mortality Asia and North Africa } \\
\text { ( } n=2 ; 4 \text { countries) } 73 \text { events }\end{array}$} & $87.9 \%(4.7-98.5 \%)$ \\
\hline \multirow{2}{*}{\multicolumn{2}{|c|}{$\begin{array}{l}\text { Developed C } \\
224 \text { events }\end{array}$}} & Countries ( $n=2 ; 7$ countries) & $90.6 \%(85.9-93.7 \%)$ \\
\hline & & $\begin{array}{r}\text { Application of } \mathrm{CH} \\
\text { Strong evidence of serious morbic }\end{array}$ & $\begin{array}{l}\text { ZG Rule s } 5 \text { and } 6 \\
\text { reduction: Highly plausible }\end{array}$ \\
\hline
\end{tabular}


disease in developing countries and the relative pathogenicity, i.e. the likelihood of individual pathogens to cause disease. Understanding why protective efficacy varies by population is critical to improve upon the currently available vaccine or to enhance the individual effect of the vaccine within different populations.

Despite the reduced effect size observed in lowincome populations, the rotavirus vaccine may still reduce rotavirus mortality by $50 \%$, an important benefit for some of the world's most vulnerable children. Rotavirus vaccine can be delivered on the routine immunization schedule providing an opportunity to prevent morbidity and mortality in areas where care seeking behaviors for diarrhea are not ideal. Preventing diarrhea mortality needs a multi-prong approach. We have numerous preventive and treatment tools, including rotavirus vaccine and oral rehydration and zinc for management of illness. Countries and international organizations need to prioritize control of diarrheal mortality as part of a comprehensive child survival strategy.

\section{Conclusions}

There is strong evidence suggesting that rotavirus vaccine decreases rotavirus specific mortality and thus all diarrhea mortality in all regions of the world. Though the effect size appears to be greater among children living in developed countries as compared to low-income countries, the increased risk of diarrhea mortality is greater in developing countries therefore increasing the justification for the continued promotion of this important child survival tool.

\section{Additional material}

Additional File 1: is an excel file and contains details of all of the studies that were abstracted, including issues related to study design and quality of data as it relates to the question of interest. Additional File 2: is an excel file and provides a summarizes the quality assessment of rotavirus vaccine trials.

\section{Acknowledgements}

The authors thank Laura Lamberti for her assistance with the figures and Loni Ajagbe for her assistance with data abstraction and figures. The study was supported by a grant from the Bill and Melinda Gates Foundation to the US Fund for UNICEF for the ongoing work of the Child Health Epidemiology Reference Group.

This article has been published as part of BMC Public Health Volume 11 Supplement 3, 2011: Technical inputs, enhancements and applications of the Lives Saved Tool (LiST). The full contents of the supplement are available online at http://www.biomedcentral.com/1471-2458/11?issue=S3.

\section{Authors' contributions}

CLFW led the analysis and wrote the first draft. REB contributed to overall study design and manuscript preparation.
Competing interests

The authors have no competing interests.

Published: 13 April 2011

\section{References}

1. Black RE, Cousens S, Johnson HL, Lawn JE, Rudan I, Bassani DG, Jha P, Campbell H, Walker CF, Cibulskis R, et al: Global, regional, and national causes of child mortality in 2008: a systematic analysis. Lancet 2010, 375(9730):1969-1987.

2. Parashar UD, Gibson CJ, Bresse JS, Glass RI: Rotavirus and severe childhood diarrhea. Emerg Infect Dis 2006, 12(2):304-306.

3. Munos MK, Walker CL, Black RE: The effect of rotavirus vaccine on diarrhoea mortality. Int J Epidemiol 2010, 39(Suppl 1):i56-62.

4. Soares-Weiser K, Goldberg E, Tamimi G, Pitan OC, Leibovici L: Rotavirus vaccine for preventing diarrhoea. Cochrane Database Syst Rev 2004, 1: CD002848.

5. Madhi SA, Cunliffe NA, Steele D, Witte D, Kirsten M, Louw C, Ngwira B, Victor JC, Gillard PH, Cheuvart BB, et al: Effect of human rotavirus vaccine on severe diarrhea in African infants. N Engl J Med 2010, 362(4):289-298.

6. Armah GE, Sow SO, Breiman RF, Dallas MJ, Tapia MD, Feikin DR, Binka FN, Steele AD, Laserson KF, Ansah NA, et al: Efficacy of pentavalent rotavirus vaccine against severe rotavirus gastroenteritis in infants in developing countries in sub-Saharan Africa: a randomised, double-blind, placebocontrolled trial. Lancet 2010, 376(9741):606-614.

7. Zaman K, Dang DA, Victor JC, Shin S, Yunus M, Dallas MJ, Podder G, Vu DT, Le TP, Luby SP, et al: Efficacy of pentavalent rotavirus vaccine against severe rotavirus gastroenteritis in infants in developing countries in Asia: a randomised, double-blind, placebo-controlled trial. Lancet 2010, 376(9741):615-623

8. Phua KB, Lim FS, Lau YL, Nelson EA, Huang LM, Quak SH, Lee BW, Teoh YL, Tang $H$, Boudville I, et al: Safety and efficacy of human rotavirus vaccine during the first 2 years of life in Asian infants: randomised, double-blind, controlled study. Vaccine 2009, 27(43):5936-5941.

9. Walker N, Fischer-Walker C, Bryce J, Bahl R, Cousens S: Standards for CHERG reviews of intervention effects on child survival. Int J Epidemiol 2010, 39(Suppl 1):i21-31.

10. Atkins D, Best D, Briss PA, Eccles M, Falck-Ytter Y, Flottorp S, Guyatt GH, Harbour RT, Haugh MC, Henry D, et al: Grading quality of evidence and strength of recommendations. BMJ 2004, 328(7454):1490.

11. de Palma O, Cruz L, Ramos H, de Baires A, Villatoro N, Pastor D, de Oliveira LH, Kerin T, Bowen M, Gentsch J, et al: Effectiveness of rotavirus vaccination against childhood diarrhoea in El Salvador: case-control study. BMJ 2010, 340:c2825.

12. Linhares AC, Velazquez FR, Perez-Schael I, Saez-Llorens X, Abate H, Espinoza F, Lopez P, Macias-Parra M, Ortega-Barria E, Rivera-Medina DM, et al: Efficacy and safety of an oral live attenuated human rotavirus vaccine against rotavirus gastroenteritis during the first 2 years of life in Latin American infants: a randomised, double-blind, placebo-controlled phase III study. Lancet 2008, 371(9619):1181-1189.

13. Vesikari T, Karvonen A, Prymula R, Schuster V, Tejedor JC, Cohen R, Meurice F, Han HH, Damaso S, Bouckenooghe A: Efficacy of human rotavirus vaccine against rotavirus gastroenteritis during the first 2 years of life in European infants: randomised, double-blind controlled study. Lancet 2007, 370(9601):1757-1763.

14. Vesikari T, Matson DO, Dennehy P, Van Damme P, Santosham M, Rodriguez Z, Dallas MJ, Heyse JF, Goveia MG, Black SB, et al: Safety and efficacy of a pentavalent human-bovine (WC3) reassortant rotavirus vaccine. N Engl J Med 2006, 354(1):23-33.

15. Lanzieri TM, Linhares AC, Costa I, Kolhe DA, Cunha MH, Ortega-Barria E, Colindres RE: Impact of rotavirus vaccination on childhood deaths from diarrhea in Brazil. Int J Infect Dis 2010.

16. Richardson V, Hernandez-Pichardo J, Quintanar-Solares M, EsparzaAguilar M, Johnson B, Gomez-Altamirano CM, Parashar U, Patel M: Effect of rotavirus vaccination on death from childhood diarrhea in Mexico. $N$ Engl J Med 2010, 362(6):299-305.

17. Lanata CF, Midthun K, Black RE, Butron B, Huapaya A, Penny ME, Ventura G, Gil A, Jett-Goheen M, Davidson BL: Safety, immunogenicity, and protective efficacy of one and three doses of the tetravalent rhesus rotavirus vaccine in infants in Lima, Peru. J Infect Dis 1996, 174(2):268-275. 
18. Patel M, Pedreira C, De Oliveira LH, Tate J, Orozco M, Mercado J, Gonzalez A, Malespin O, Amador JJ, Umana J, et al: Association between pentavalent rotavirus vaccine and severe rotavirus diarrhea among children in Nicaragua. JAMA 2009, 301(21):2243-2251.

19. Snelling TL, Schultz R, Graham J, Roseby R, Barnes GL, Andrews RM, Carapetis JR: Rotavirus and the indigenous children of the Australian outback: monovalent vaccine effective in a high-burden setting. Clin Infect Dis 2009, 49(3):428-431.

20. Levine MM: Immunogenicity and efficacy of oral vaccines in developing countries: lessons from a live cholera vaccine. BMC Biol 2010, 8:129.

21. Correia JB, Patel MM, Nakagomi O, Montenegro FM, Germano EM,

Correia NB, Cuevas LE, Parashar UD, Cunliffe NA, Nakagomi T: Effectiveness of monovalent rotavirus vaccine (Rotarix) against severe diarrhea caused by serotypically unrelated G2P[4] strains in Brazil. J Infect Dis 2010, 201(3):363-369.

doi:10.1186/1471-2458-11-S3-S16

Cite this article as: Fischer Walker and Black: Rotavirus vaccine and diarrhea mortality: quantifying regional variation in effect size. $B M C$ Public Health 2011 11(Suppl 3):S16.

\section{Submit your next manuscript to BioMed Central} and take full advantage of:

- Convenient online submission

- Thorough peer review

- No space constraints or color figure charges

- Immediate publication on acceptance

- Inclusion in PubMed, CAS, Scopus and Google Scholar

- Research which is freely available for redistribution

Submit your manuscript at www.biomedcentral.com/submit
C Biomed Central 